Athanasios Kambylis

Graeca - Byzantina - Neograeca 


\section{Supplementa Byzantina}

Texte und Untersuchungen

Herausgegeben von Athanasios Kambylis Band 11 


\section{Athanasios Kambylis \\ Graeca - Byzantina - Neograeca}

Schriften zur griechischen Sprache und Literatur

Herausgegeben von

Foteini Kolovou und Günter Prinzing 
ISBN 978-3-11-063328-3

e-ISBN (PDF) 978-3-11-063994-0

e-ISBN (ePUB) 978-3-11-063607-9

ISSN 0933-5080

Library of Congress Cataloging in Publication Control Number: 2019931229

\section{Bibliografische Information der Deutschen Nationalbibliothek}

Die Deutsche Nationalbibliothek verzeichnet diese Publikation in der Deutschen Nationalbibliografie; detaillierte bibliografische Daten sind im Internet über http://dnb.dnb.de abrufbar.

(C) 2020 Walter de Gruyter GmbH, Berlin/Boston

Druck und Bindung: $\mathrm{CPI}$ books $\mathrm{GmbH}$, Leck

www.degruyter.com 